\title{
COMPARISON OF VOLATILE COMPONENTS FROM MARCHANTIA CONVOLUTA OBTAINED BY MICROWAVE EXTRACTION AND PHYTOSOL EXTRACTION
}

\author{
CHEN YAN, JIANG XING YU, TONG XING, CHEN XIAO QING* \\ College of Chemistry and Chemical Engineering, Central South University, Changsha 410083, PR China \\ (Received: 18 April 2007 - Accepted: 20 March 2008)
}

\begin{abstract}
The volatile oils from Marchantia convoluta were obtained by microwave extraction (ME) and phytosol extraction (PE) methods. The attained extracts were analyzed by gas chromatography with mass spectrometric detector (GC-MS). The compounds were identified according to their retention indices and mass spectra (EI, $70 \mathrm{eV}$ ). A total of fourteen compounds were identified in ME extract accounting for $80.72 \%$ of total peak area. Isolongifolene (24.588\%), 1, 2benzenedicarboxylic acid, butyl cyclohexyl ester (10.768\%), pyrene $(9.328 \%)$ and hexadecanoic acid, ethyl ester $(8.570 \%)$ were the major compounds identified from ME extract. The analytical results of ME extract were compared with PE method. The ME extract was found to be markedly different from that of PE extract. A total of seven compounds in PE extract were identified accounting for $74.275 \%$ total peak area. 1-Phenanthrenecarboxylic acid, 1,2,3,4,4a,9,10, 10a-octahydro1, 4a-dimethyl-7-(1-methylethyl) methyl ester were the major compounds.
\end{abstract}

\section{INTRODUCTION}

Marchantiaceae plants are well-known traditional Chinese medicinal herbs and extensively used to treat tumefaction of skins, protect liver and treat hepatitis and used as antipyretic in countryside ${ }^{1-3}$. There are a large number of Marchantiaceae plants in Guangxi Zhuang Autonomous District such as Marchantia polymorpha, M. convoluta and M. paleacea. These species grow together and it is difficult to distinguish one from the others because of their genetic similarity. M. convoluta was only found in China ${ }^{4}$.

The major identified constituents in M. convoluta were flavonoids, triterpenoids, and steroids ${ }^{5-9}$. The dried leaves were used in China to protect the liver and to treat tumefaction of skins. A high dosage of flavonoids from M. convoluta (20 and $40 \mu \mathrm{g} / \mathrm{mL}$ ) can significantly reduce the activity of ALT (Alanine aminotranferease) and AST (Alanine aminotranferease) in the serum of mice with acute hepatic injury caused by $\mathrm{CCl}_{4}$ and increase the contents of TP (Total protein) and ALP (Alkaline phosphatase), as well as inhibit the auricle tympanites of mice caused by dimethylbenzene ${ }^{1}$. Flavonoids from $M$. convoluta strongly inhibited bacteria, anti-inflammation and diuresis in mice', as well as flavonoids from M. convoluta have anti-hepatitis B Virus activity ${ }^{2}$. The ethyl acetate extract from M. convoluta strongly inhibited tumors in human liver and lung cancer cell lines ${ }^{3,11}$. Flavonoids from M. convoluta strongly inhibit Staphylococcus aureus ${ }^{1,10}$.

The microwave and phytosol extraction methods for extracting essential oils have attracted great interest among researchers ${ }^{12-14}$. The main virtue of the microwave technique is cost-effective and simple. In recent years, head space solid phase micro-extraction (HS-SPME) has gained wide acceptance as an effective extraction technique for a wide variety of samples ${ }^{15-16}$. HS-SPME is performed by exposing a fiber coated with single or multiple polymers to the headspace of a sample matrix until equilibrium is reached between the analyte partitioned in the fiber coating and the analyte in the sample matrix ${ }^{17-18}$.

Phytosol solvents are a new range of benign, non-CFC solvents, commercially available for the extraction of analytes from natural products, foods and environmental matrices ${ }^{19}$. Phytosol extraction (PE) is a new portable cold extraction technique without heat.

The aim of the present work was the investigation of the volatile components from M. convoluta obtained by Microwave-assisted solid phase micro-extraction (MPME) and Phytosol extraction (PE).

\section{Materials and methods}

\section{Plant materials}

The whole plants of M. convoluta were collected in Shangling City of Guangxi Zhuang Autonomous District in August 2003. The specimen (No. 20041364) was identified by Zhou Zi-jing, at the Biology Department of Guangxi Chinese Medical University. The dried leaves were stored in a dark place at $4{ }^{\circ} \mathrm{C}$ for $20 \mathrm{~d}$. Immediately prior to the extraction process, the leaves were ground in a blender to produce a powder with an approximate size of $0.4 \mathrm{~mm}$.

\section{Reagents}

Analytical grade methanol was purchased from Hanbon Company Limited (Jiangsu, China). Carbon dioxide (99.99\% purity), contained in a cylinder with an eductor tube, was obtained from CSU (Changsha, China). Phytol, cedrol, stigmasterol, 22, 23-dihydro-stigmasterol, and other organic compounds used to identify in GC/MS, were purchased from Sigma (USA). Phytosol solvent

(99.9\% purity) was purchased from Hua Xue Company.

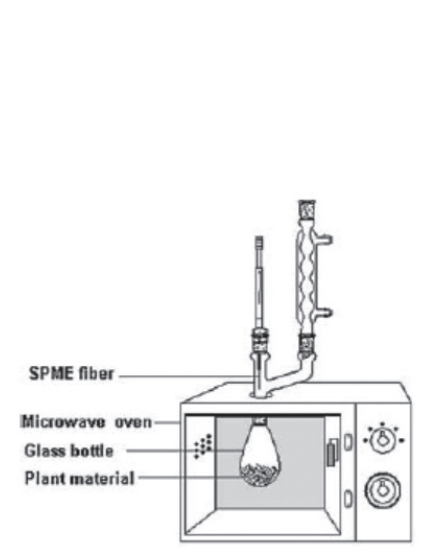

a

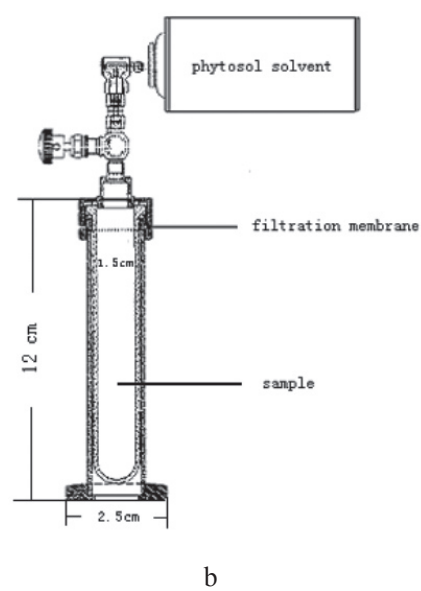

Fig. 1. The equipments of $\operatorname{ME}(a)$ and $\operatorname{PE}(b)$

\section{Apparatus}

The home-made microwave extraction apparatus was illustrated in Fig. 1. The microwave oven (WD800CTL23-2H, maximum delivered power 650 W) was purchased from Galanz. The self-made phytosol solvent extraction apparatus was illustrated in Fig. 2.

\section{Microwave extraction (ME)}

Since various parameters potentially affected the extraction process, the optimization of the experimental conditions represents a critical step in the development of a microwave extraction method. The optimized condition was following: $10 \mathrm{~g}$ of dried materials was soaked in $200 \mathrm{ml}$ acetic ester for $24 \mathrm{~h}$, and irradiated in microwave oven for $120 \mathrm{~s}$. The extraction was repeated for three times and the extracted solvent was collected in beaker after filtration

\section{Phytosol extraction (PE)}

A known quantity of powdered $M$ convoluta (approximately $10 \mathrm{~g}$ ) was placed in the extraction vessel with a filter adapter, and then the phytosol solvent $(10 \mathrm{ml})$ was introduced into the vessel. The assembled extraction cell was shaken periodically for $1 \mathrm{~h}$ at room temperature. Then the extraction cell was inverted and the filter adapter was attached. By careful opening of the tap on the filter adapter, phytosol solvent containing the volatile components was collected in the sealed container. This solvent can cause freezing the glass collector. After standing for a few minutes in an ambient laboratory temperature, the phytosol solvent was removed using a recycling device that preferentially used to remove the solvent leaving in the collector. The extraction procedure was repeated thee times per sample. Then the sample residues were dissolved in methanol, quantitatively transferred into a volumetric flask (25 $\mathrm{ml}$ ) and made up to volume using methanol. Prior to analysis the sample was diluted 10 times. 
6. Gas chromatography-mass spectrometry

GC analyses were performed using a Shimadzu GC-9A gas chromatograph equipped with a FID and a HP-5 fused silica column $(60 \mathrm{~m} \times 0.25 \mathrm{~mm}$ i.d., $0.25 \mathrm{~mm}$ film thickness) with a $5 \%$ (mole fraction) phenyl-substituted methylpolysiloxane phase. Oven temperature was programmed $60{ }^{\circ} \mathrm{C}$ for 5 min, and then increased to $250{ }^{\circ} \mathrm{C}$ at a rate of $5{ }^{\circ} \mathrm{C} / \mathrm{min}$. Injector and detector temperatures were 250 and $265^{\circ} \mathrm{C}$, respectively. The carrier gas, helium, was adjusted to a linear velocity of $30 \mathrm{~cm} / \mathrm{s}$. The sample $(1 \mu \mathrm{L})$ was injected into GC/MS using the split mode with a split ratio of $1 / 60$. The ionization energy was $70 \mathrm{eV}$ with a scan time of $1 \mathrm{~s}$ and mass range of $40-540 \mathrm{amu}$. The percentages of compounds were calculated by the area normalization method without considering response factors. The components of the oil were identified by comparison of their mass spectra with those of the spectrometer database using the Wiley $275 \mathrm{~L}$ mass spectral database or with authentic compounds. The identifications were confirmed by comparison of the fragmentation pattern and their retention indices with those reported in the literature ${ }^{20,21}$.

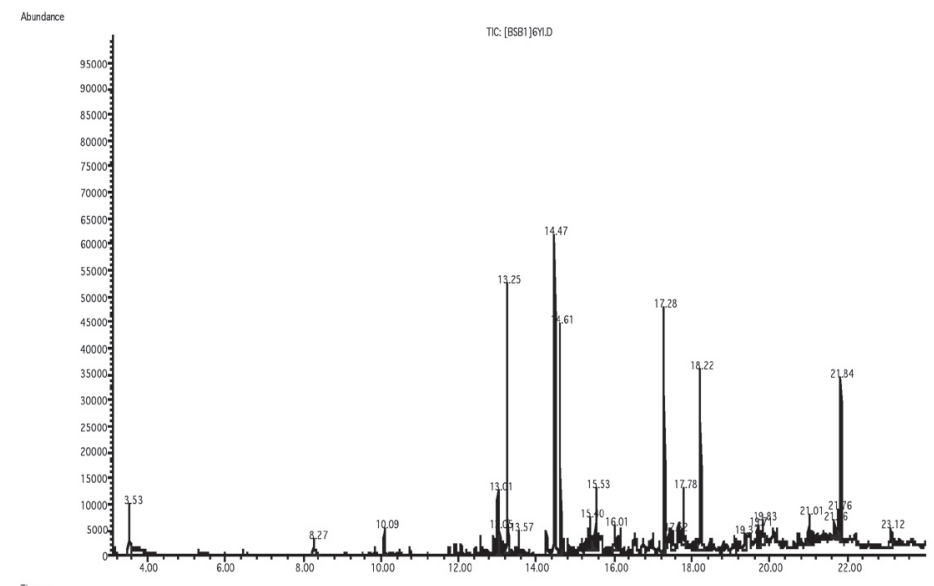

Fig. 2. GC-MS profiles of ME extract.

Table 1 GC-MS analytical results of $M$. convoluta oils obtained by ME

\begin{tabular}{lllll}
\hline \multirow{2}{*}{ No. } & \multicolumn{1}{c}{ Compound } & $\begin{array}{l}t_{R} \\
(\min )\end{array}$ & Match (\%) & $\begin{array}{l}\text { Relative } \\
\text { amount (\%) }\end{array}$ \\
\hline 1 & 2-Propenoic acid, butylester & 3.53 & 91.2 & 3.343 \\
2 & 2,6,11-trimethyl-Dodecane & 10.09 & 85.1 & 1.773 \\
3 & Dodecanal & 11.91 & 81.0 & 1.131 \\
4 & Eicosane & 13.01 & 86.1 & 2.704 \\
5 & Nonadecane & 13.05 & 75.2 & 1.424 \\
6 & 2,4-bis(1,1-dimethylethyl)-Phenol & 13.25 & 94.2 & 10.808 \\
7 & 2,6,11,15-tetramethyl-Hexadecane & 13.57 & 84.4 & 1.196 \\
8 & Hexadecane & 14.25 & 78.5 & 1.138 \\
9 & Isolongifolene & 14.47 & 70.9 & 24.588 \\
10 & Eicosane & 16.01 & 83.1 & 2.653 \\
11 & 1,2-Benzenedicarboxylic acid, butyl cyclohexyl ester & 17.28 & 90.6 & 10.768 \\
12 & 2,6,10,15-tetramethyl-Heptadecane & 17.52 & 82.6 & 1.296 \\
13 & Pyrene & 18.22 & 90.9 & 9.328 \\
14 & Hexadecanoic acid, ethyl ester & 21.84 & 89.6 & 8.570 \\
\hline
\end{tabular}

Compounds were listed in order of elution time.

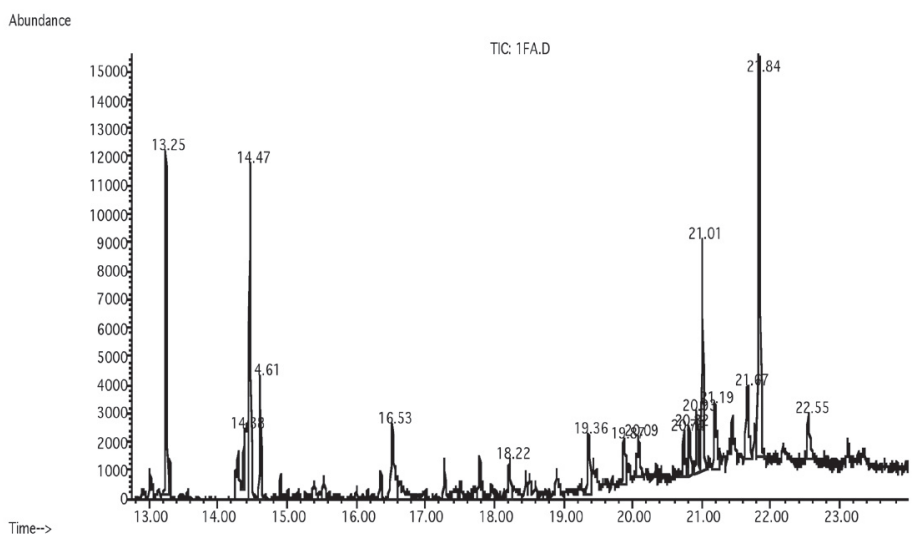

Fig. 3. GC-MS profiles of PE extract. 
Table 2.- GC-MS analytical results of M. convoluta oils obtained by PE (compounds were listed in order of elution time)

\begin{tabular}{|l|l|l|l|l|}
\hline No. & \multicolumn{1}{|c|}{ Compound } & $\begin{array}{l}t_{R} \\
(\mathrm{~min})\end{array}$ & $\begin{array}{l}\text { Match } \\
(\%)\end{array}$ & $\begin{array}{l}\text { Relative } \\
\text { amount (\%) }\end{array}$ \\
\hline 1 & 2,4-bis(1,1-dimethylethyl) -Phenol & 13.25 & 93.3 & 9.856 \\
2 & Isolongifolene & 14.47 & 61.8 & 11.74 \\
3 & 9-methylene-9H-Fluorene & 16.53 & 90.9 & 5.615 \\
4 & 1,2-Benzenedicarboxylic acid, butyl cyclohexyl ester & 18.22 & 80.1 & 1.872 \\
5 & Pyrene & 19.36 & 87.9 & 3.432 \\
6 & $\begin{array}{l}\text { 1-Phenanthrenecarboxylic acid, 7-ethenyl-1,2,3,4,4a,4b,5,6,7,8,10,10a- } \\
\text { dodecahydro-1,4a,7-trimethyl, methyl ester }\end{array}$ & 21.01 & 73.7 & 7.552 \\
& 1-Phenanthrenecarboxylic acid, 1,2,3,4,4a,9,10,10a-octahydro-1,4a-dimethyl- & & & \\
& 7-(1-methylethyl), methyl ester & 21.84 & 90.1 & 34.208 \\
\hline
\end{tabular}

Compounds were listed in order of elution time.

\section{RESULTS AND DISCUSSION}

\section{GC-MS analyses}

The volatile components in $M$ convoluta were isolated, extracted, and concentrated by ME method and the analytes were then analyzed by GC-MS. The chemical components of the essential oil were identified from their retention indices and by mass spectral database search (Fig. 2). Twenty-three compounds were separated and fourteen compounds were identified by reference standards (Table 1). The peak area of compounds identified accounted for $80.72 \%$ of total peak area. One of terpene, six of alkane, five of oxygen-containing compounds and one other compound were attained. The most abundant eight compounds were in the descending order: isolongifolene $(24.588 \%), 2,4$ bis(1,1-dimethyleth-yl)-phenol (10.808\%), 1,2-Benzenedicarboxylic acid, butyl cyclohexyl ester $(10.768 \%)$, pyrene $(9.328 \% \%)$, and hexadecanoic acid, ethyl ester $(8.570 \%)$.

The components of essential oil obtained from M convoluta by PE method were showed in Table 2. The chemical components of the essential oil were identified from their retention indices and by mass spectral database search (Fig. 3). It can be seen that, sixteen compounds were separated by HP-5 column and seven compounds were identified by reference standards. The peak area of compounds identified accounted for $74.275 \%$ of total peak area. The major compounds were 1-phenanthrenecarboxylic acid, 1,2,3,4,4a,9,10,10aoctahydro-1,4a-dimethyl-7-(1-methylethyl)-methyl ester (34.208\%), isolongifolene ( $11.74 \%$ ) and 2,4-bis(1,1-dimethylethyl)- phenol (9.856\%).

M. convoluta was found only in China. There are few reports about the chemical components of its essential oils. Only the essential oils of $M$ convoluta obtained by petrol ether extraction and supercritical (carbon dioxide) extraction methods have been reported by $\mathrm{Cao}$ et $\mathrm{al}^{6,10}$. There are may be some novel compound essential oils of M. convoluta. Using only GC-MS, it has not been possible to identify all of the compounds in the essential oil of $\mathrm{M}$. convoluta. Isolation and identification of chemical components from $M$. convoluta need further work.

\section{Comparison of ME and PE methods}

ME offers a rapid delivery of energy to the solvent and microwave radiation can be focused directly onto the sample, thus the heating is more efficient. the cell walls of the plants was disrupted mainly due to the mechanical effects of micromave cavitation, which can observed legibly under the microscope. In this study, we present ME as an "environmentally friendly" extraction method suitable for sample preparation prior to essential oil analysis. ME is a very clean method, which avoids the use of large quantity of water and voluminous extraction vessels (HD). ME could also be used to produce larger quantities of essential oils by using existing big scale microwave extraction reactors. These microwave reactors are suitable for the extraction of 10,20 or $100 \mathrm{~kg}$ of fresh plant material per time. Theses reactors could be easily modified and used for ME extractions.

Compared with ME, the virtue of PE was its low temperature. Moreover it is convenient for industrial application. An essential drawback in the use of phytosol is its low polarity, making the extraction of polar analytes difficult. Moreover the PE equipment is comparatively hard to control the reacting pressure and temperature. In the present work, the higher polar components such as isolongifolene $(24.59 \%)$ and dodecanal $(1.13 \%)$ were largely found in the ME extract. Because it is lower polarity for petrol ether, the lower polar compounds were the main components in petrol ether extraction. This limitation can be overcome by means of addition of polar modifiers, such as methanol or ethanol to the phytosol solvent. In the present work, the higher polar components such as isolongifolene (24.588\%) and dodecanal (1.131\%) were largely found in the ME extract.

\section{Comparison with Literature Results}

Extraction of natural products by different methods may yield different chemical components ${ }^{22-27}$. There were few reports about the chemical components from M. convoluta. Cao et al extracted the volatiles from leaves of M. convoluta by petrol ether extraction (PEE) and supercritical carbon dioxide extraction (SFE). As shown in Table 3, the volatiles from M. convoluta by ME, PE, PEE and SFE are significantly different from each other. Higher levels of ester and organic acids were found in the PEE and the ME extracts. However, higher levels of terpenes (accounting for $24.59 \%$ ), which weren't found previously in $M$. convoluta essential oils, were also found in the ME extracts.

PE appears to be a cost-effective technique in laboratory scale, but an accurate economic evaluation for large-scale units requires supplementary experiments. PE also can be considered as a kind subcritical fluid extraction. The advantages of PE over the PEE include: low operating temperature, hence no thermal degradation of most of the labile compounds; shorter extraction period; high selectivity in the extraction of compounds; no solvent residue with negative effects on the oils quality. The volatiles of plants have usually been isolated by either hydrodistillation or solvent extraction. The disadvantages of all these techniques are: low yield, loss of volatile compounds, long extraction time, toxic solvent residues and degradation of unsaturated compounds, giving undesirable off-flavour compounds, due to heat.

In the SFE-CO technique, the extraction is controlled by molecular diffusion rates. The fluid density is proportional to the extraction pressure and directly related to the chemical composition of the volatile fraction obtained. At high pressure (more than $20 \mathrm{MPa}$ ), the fluid has a low selectivity leading to extraction of a large variety of relatively heavy compounds (stigmasterol, fatty acids). However, PE is a cold extraction technique without heat. The PE system used in this work is a low pressure extraction unit. The pressure of PE is only 3-4 MPa. So the extraction selectivity of PE increased and no relatively heavy compounds, such as fatty acids were extracted. The main virtue of the $\mathrm{PE}$ technique over SFE- $\mathrm{CO}_{2}$ extraction is convenience, easy separation, and easy reclaim. The PE apparatus is also simper than that of $\mathrm{SFE}-\mathrm{CO}_{2}$.

The ME method offers obvious advantages over petrol ether extraction, namely: shorter extraction time (120 s against $72 \mathrm{~h}$ for PEE); lower cost (energy cost is fairly higher for SFE- $\mathrm{CO}_{2}$ ) and cleaner features (large volumes of organic solvents are avoided). 
Table 3.- Analytical results of M. convolute oils obtained by SFE, PEE,ME and PE

\begin{tabular}{|c|c|c|c|c|c|}
\hline \multirow[b]{2}{*}{ No. } & \multirow[b]{2}{*}{ Compound } & \multicolumn{4}{|c|}{ Relative content $(\%)$} \\
\hline & & SFE & PEE & ME & PE \\
\hline 1 & Benzoic acid & 1.14 & - & - & - \\
\hline 2 & Methylsalicylate & 1.41 & 0.77 & - & - \\
\hline 3 & Dodecamethylcyclohexasiloxane & 1.23 & - & - & - \\
\hline 4 & Decamethylcycloheptasiloxane & 1.35 & - & - & - \\
\hline 5 & Diethylphthalate & 1.46 & - & - & - \\
\hline 6 & Cedrol & - & 1.21 & - & - \\
\hline 7 & Eudesma-4,11-diene & - & 0.88 & - & - \\
\hline 8 & Tributylphosphine oxide & 4.61 & - & - & - \\
\hline 9 & Dibutylphthalate & 0.61 & 1.19 & - & - \\
\hline 10 & n-Hexadecanoic acid & 20.35 & 1.41 & - & - \\
\hline 11 & E-11-hexadecenoic acid ethyl & - & 9.77 & - & - \\
\hline & Ester & & & - & - \\
\hline 12 & Hexadecanoic acid ethyl ester & - & 36.97 & 8.570 & - \\
\hline 13 & Phytol & - & 7.74 & - & - \\
\hline 14 & Linoleic acid ethyl ester & - & 4.63 & - & - \\
\hline 15 & Ethyloleate & 5.75 & 10.47 & - & - \\
\hline 16 & Octadecanoic acid & 4.55 & - & - & - \\
\hline 17 & Stigmasterol & 31.26 & - & - & - \\
\hline 18 & 22,23-dihydro-stigmasterol & - & - & - & - \\
\hline 19 & 2-Propenoic acid, butyl ester & - & - & 3.343 & - \\
\hline 20 & 2,6,11-trimethyl-Dodecane & - & - & 1.773 & - \\
\hline 21 & Dodecanal & - & - & 1.131 & - \\
\hline 22 & Eicosane & - & - & 2.704 & - \\
\hline 23 & Nonadecane & - & - & 1.424 & - \\
\hline 24 & 2,4-bis(1,1-dimethylethyl)-Phenol & - & - & 10.808 & 9.856 \\
\hline 25 & 2,6,11,15-tetramethyl-Hexadecane & - & - & 1.196 & \\
\hline 26 & Hexadecane & - & - & 1.138 & \\
\hline 27 & Isolongifolene & - & - & 24.588 & 11.74 \\
\hline 28 & Eicosane & - & - & 2.653 & \\
\hline 29 & $\begin{array}{l}\text { 1,2-Benzenedicarboxylic acid, butyl } \\
\text { cyclohexyl ester }\end{array}$ & - & - & 10.768 & 1.872 \\
\hline 30 & 2,6,10,15-tetramethyl-Heptadecane & & - & 1.296 & \\
\hline 31 & Pyrene & - & - & 9.328 & 3.432 \\
\hline 32 & 9-methylene-9H-Fluorene & - & - & - & 5.615 \\
\hline 33 & $\begin{array}{l}\text { 1-Phenanthrenecarboxylic acid, 7- } \\
\text { ethenyl-1,2,3,4,4a,4b,5,6,7,8,10,10a- } \\
\text { dodecahydro-1,4a,7-trimethyl,methyl } \\
\text { ester }\end{array}$ & - & 36.97 & - & 7.552 \\
\hline 34 & $\begin{array}{l}\text { 1-Phenanthrenecarboxylic acid,1,2, } \\
\text { 3,4,4a,9,10,10a-octahydro-1,4a- } \\
\text { dimethyl-7-(1-methylethyl), methyl ester }\end{array}$ & - & - & - & 34.208 \\
\hline
\end{tabular}

\section{CONCLUSIONS}

The ME and PE of essential oil in M. convoluta has been studied. The results showed that isolongifolene was the main component in the ME extract. The coumpounds in volatile oils of $M$. convoluta obtained by ME and PSE were different from the literature. The ME method offers obvious advantages over petrol ether extraction, namely: shorter extraction time $(4 \mathrm{~h}$ against $72 \mathrm{~h}$ for petrol ether extraction); lower cost (energy cost is fairly higher for performing petrol ether extraction than that required for reaching supercritical conditions) and cleaner features (large volumes of organic solvents are avoided). The main component found in the PSE essential oil was 1-Phenanthrenecarboxylic acid, 1,2,3,4,4a,9,10,10a-octahydro-1,4a-dimethyl-7-(1-methylethyl)-, methyl ester. The advantages of the PSE were convenience and simple.

\section{ACKNOWLEDGMENTS}

The authors are grateful for financial supported by National Natural Science Foundation of China (grant No. 20775092).

\section{REFERENCES}

1. Xiao, J.B., Jiang, X.Y., Chen, X.Q., Afr. J. Traditional Complement. Alterna. Med. 2, 244, (2005).

2. Xiao, J.B., Ren, F.L., Jiang, X.Y., Xu, M., Iran. J. Pharmacol. Therapeut. 4, 128, (2005).

3. Chen, X.Q., Xiao, J.B.,. Afr. J. Traditional Complement. Altern. Med. 3, 32, (2006).

4. Tian, C.Y., Wu, J.Q., Liu S.X, Hu, R.L., J. Wuhan Botan. Res. 17, 146, (1999).

5. Cao, H., Xiao, J.B., Zhou, C.S., Zhang, Y.W., J. Chin. Mass Spectr. Soc. 26, 1, (2005).

6. Cao, H., Xiao, J.B, Xu, M., J. Food Compos. Anal. 20, 45, (2007)

7. Chen, X.Q., Xiao, J.B., Iran. J. Pharm. Res. 4, 175, (2005).

8. Xiao, J.B., Chen, J.W., Xu, M., Electron. J. Biotechn. 10, 141, (2007).

9. Cao, H., Ji, M.J., Wang, H.X., J. Chil. Chem. Soc. 52, 1088, ( 2007).

10. Xiao, J.B., Chen, J.W., Ren, F.L., Yang, C.S., Xu, M., Anal. Chim. Acta 589, 186, (2007).

11. Xiao, J.B., Chen, X.Q., Zhang, Y.W., Xu, M., Braz. J. Med. Biol. Res. 39, 731, (2006). 
12. Alvarez-Aviles, O., Cuadra-Rodriguez, L., Gonzalez-Illan, F., QuinonesGonzalez, J., Rosario, O., Anal. Chim. Acta 597, 273, (2007).

13. Villar, M., Callejon, M., Jimenez, J.C., Alonso, E., Guiraum, A., Anal. Chim. Acta 599, 92, (2007).

14. Lucchesi, M.E., Jacueline, S., Bradshwa, S., Louw, W., Chemat F., J. Food Compos. Anal. 79, 1079, (2007).

15. Bagheri, H., Es-haghi, A., Khalilian, F., Rouini, M.R., J. Pharm. Biomed. Anal. 43, 1763, (2007).

16. Fedrizzi, B., Versini, G., Lavagnini, I., Nicolini, G., Magno, F., Anal. Chim. Acta 596, 291, (2007).

17. Chen, W.C,. Zhou, P.Z., Wong-Moon, K.C., Cauchon, N.S., J. Pharm. Biomed. Anal. 44, 450, (2007).

18. Yarramraju, S., Akurathi, V., Wolfs, K., Van Schepdael, A., Hoogmartens, J., Adams, E., J. Pharm. Biomed. Anal. 44, 456, (2007).

19. Dean, J.R., Liu, B., Price, R., J. Chromatogr. A 799, 343, (1998).

20. Sandra, P., Bicchi, C., Huthig Fachverlage Vertrieb, NewYork (1987).
21. Adams, R.P., Identification of essential oil components by gas chromatography/ quad rupole masss pectroscopy. Allured Publishing Corporation,Carol Stream, IL, USA. (2001).

22. Marongiu, B., Piras, A., Porcedda, S., Tuveri, E., Sanjust, E., Meli, M., Sollai, F., Zucca, P., Rescigno, A., J. Agri. Food Chem. 55, 10022, (2007).

23. Da Silva, J.K.R., Sousa, P.J.C., Andrade, E.H.A., Maia, J.G.S., J. Agri. Food Chem. 55, 9422, (2007).

24. El-Ghorab, A., El-Massry, K.F., Shibamoto, T., J. Agri. Food Chem. 55, 9124, (2007).

25. Jurado-Sanchez, B., Ballesteros, E., Gallego, M., J. Agri. Food Chem. 55, 9758, (2007).

26. Burkhardt, S., Bohm, V., J. Agri. Food Chem. 55, 8295, (2007).

27. Urzua, A., Santander, R., Echeverria, J., J. Chil. Chem. Soc. 52, 1244, (2007). 